\title{
Efficiency Assessment across Homogeneous Specialty Clinics in the Region of Thessaly, Greece
}

\author{
M. Geitona ${ }^{1}$, L. Androutsou*,2, and J. Yfantopoulos ${ }^{3}$ \\ ${ }^{1}$ School of Social and Educational Policy, University of Peloponnese, Kolokotroni \& Damaskinou str., Korinth, 20100 \\ Greece \\ ${ }^{2}$ Department of Economics, University of Thessaly, Argonafton \& Filellinon Volos, 38221, Greece \\ ${ }^{3}$ School of Law, Economics and Political Science, University of Athens, 6 Pandoras str., 14578 Ekali Athens, Greece
}

\begin{abstract}
Background: Hospital care expenditure is the most significant cost driver in the health care sector. Reductions in public hospitals' expenses are among the principal austerity measures included in the memorandum recommendations. However, health policy decision-making seems to be a political rather than a technical issue.

Objective: The aim of this paper is to assess performance by using Data Envelopment Analysis(DEA) among homogeneous specialties in the General Medicine(GM) and surgical clinics, across all hospitals operating in the Regional Health Authority of Thessaly(RHAT), over the period of 2002-2006.

Methods: Two output-oriented DEA models have been adapted, separated in homogeneous GM and surgical clinics, for both constant(CRS) and variable returns to scale(VRS). The unit of analysis is the clinic. A total of 175 decision-making units(DMUs) have been composed. The number of inpatients and inpatient days are considered as outputs whereas the number of the personnel employed and beds as labour and capital inputs respectively.

Results: Highest efficiency scores overtime were achieved by the GM clinics of the University District Hospital of Larissa. In surgical specialties, the ophthalmology clinic of the general hospital(GH) of Larissa and the urology of GH of Karditsa achieved the highest efficiency scores. Inefficiencies among GM and surgical clinics per year were also found. Both homogeneous groups followed similar trends in the curves. Five GM and ten surgical DMUs under both VRS and CRS remained fully efficient.
\end{abstract}

Conclusions: The economic crisis Greece is facing, necessitates the assessment of National Health System(NHS) hospitals' performance in order to support health policy decision-making and resources allocation.

Keywords: Data Envelopment Analysis, Efficiency, Greece, Hospital Performance, Measurement.

\section{INTRODUCTION}

Measures of hospital efficiency play an important role in the evaluation of health policy interventions and in the process of resources' allocation [1]. A common objective across health care systems is to improve the quality and efficiency of the services provided by applying specific managerial techniques [2-7]. Hospitals are the most costly producers in the health care sector and do not adhere to the typical optimising economic behaviour. Inefficiencies related to the excessive and incorrect input utilisation, contribute to the escalation of hospitalisation costs [8].

Much of the research on hospital performance has focused on the measurement of efficiency through frontier methods such as DEA [9-22]. DEA methodology for measuring hospital efficiency is a non-parametric mathematical

*Address correspondence to this author at the Rue des Aubepines, L-1145, Luxembourg; Tel: 00352691717566; Fax: 00302410232373:

E-mail: landroutsou@gmail.com programming technique, developed by Charnes et al (1978) [15]. DEA is a multi-criterial approach, capable of handling multiple inputs and outputs expressed in different measurement units $[17,19,23-30]$. It assesses the relative efficiency of a set of similar decision-making units (DMUs) $[15,18-21,31-33]$. DEA is equivalent to a set of traditional linear programming models in which the decision units' input and output weights are treated as the decision variables. DEA models can be either input or output oriented. In DEA studies applied to the hospital sector, a vector of inputs and intermediate outputs referring to a set of hospitals/clinics are analysed with the aim of identifying the relatively most efficient DMUs in the set. The computation of DEA can be performed under both variable returns to scale (VRS) and constant returns to scale (CRS). The CRS score captures global (in)efficiency, whereas the VRS and the "scale" scores decompose the global score into pure technical efficiency and scale efficiency, respectively $[10,15,30]$. Technical efficiency refers to the conversion of inputs into outputs relative to best practice. It provides the 
ability of a producer to avoid waste by producing as much output as input allows, or by using as little input as output production allows [15] and it depends on the input-output ratio of productivity [33]. Scale efficiency change measures whether production becomes more (less) scale efficient (e.g. optimal size - number of beds). VRS is an extension performed [10] to the original paper of CRS [15] accommodating a model which may be appropriate when not all DMUs can be considered to be operating at an optimal level.

Studies in efficiency measurement in the hospital sector have been conducted in several countries [32-63]. Hospital performance has been a subject of great interest in the international literature with the majority of the studies making use of the hospital as the DMUs [32-34, 39, 41, 42, $45,46,51]$. Limited bibliography has been published in assessing efficiency at the clinical level by running DEA, and even less in examining the performance across homogeneous clinics in Greece [38,40,50-53]. However, several studies have been conducted in Greece, aiming at the assessment of hospital efficiency using both parametric [54$58]$ and non-parametric techniques $[35,43,44,47,48,59,60-$ 63]. Despite the variation in the methodologies used, the findings of the above mentioned studies coincide in hospital inefficiencies [35, 43, 44, 47, 48, 54-59, 60-63]. These inefficiencies have resulted in accumulated hospital deficits [36,64-68] of more than six billion euros in 2010, dramatically affecting the overall national economy. Total public hospitals' expenses reached 2.6 billion euros in 2010 , while, the IMF and EU memorandum recommends their decrease by 500 million euros by the end of $2012[69,70]$. Taking the above into consideration, it is necessary to assess hospital performance in order to improve and support decision-making as well as resources' allocation.

The aim of this paper is to assess hospital performance by using DEA among homogeneous specialties in the GM and surgical clinics, across all hospitals operating in the Regional Health Authority of Thessaly (RHAT), over the period of 2002-2006. The rationale underpinning DEA is to identify options to optimize efficiency in the hospital clinics and take a broader perspective on the long term input for the improvement of the NHS hospitals' management. The absence of a systematic and comparative hospitals' performance assessment has resulted not only in the application of flat cuts across all hospital budgets regardless of their performance, the socioeconomic environment of the region and the target population, but also in the avoidance of rewarding clinics/hospitals that achieved high performance. Therefore, DEA creates opportunities for potential applicability of efficiency measurement models in Greece in order NHS hospitals' funding and decision-making to be based on their performance in a comparable and transparent way.

\section{MATERIAL AND METHODOLOGY}

The computation of hospital/clinic efficiency has been explored by using the non-parametric mathematical programming approach - DEA. Efficiency measurement refers to technical efficiency (TE), which aims at the maximisation of outputs for a given level of inputs, or conversely the minimisation of input use for a given output level $[15,22,33,71]$. In this study, an output-oriented measure has been performed in order to evaluate by how much quantities can be proportionally increased without changing the input quantities used [13,15,71-73]. The formulation of an output-oriented model has been widely adopted in the health care sector $[13,15,38-40,43-46,50,72,73]$. The formulation used to define efficiency in this study is described as follows:

In order to characterise production technology related to the efficiency measurement, each clinic uses variable inputs $\chi=\left(\chi_{1}, \ldots, \chi_{\mathrm{N}}\right) \in \mathrm{R}^{\mathrm{N}}$ + to produce variable outputs $\mathrm{y}=$ $\left(\mathrm{y}_{1}, \ldots, \mathrm{y}_{\mathrm{M}}\right) \in \mathrm{R}^{\mathrm{M}}+$. The clinic inputs can be transformed into outputs using technology that can be described by GR = $\{(\mathrm{x}, \mathrm{y})$ : $\mathrm{x}$ can produce $\mathrm{y}\}$. Corresponding to the GR, there is a family of input sets $\mathrm{L}(\mathrm{y})=\{\mathrm{x}(\mathrm{x}, \mathrm{y}) \in \mathrm{GR}\}, \mathrm{y} \in \mathrm{R}^{\mathrm{M}}{ }_{+}$. Input sets are assumed to be closed and bounded above, and to satisfy strong disposability of inputs. The input sets contain isoquants Isoq $\mathrm{L}(\mathrm{y})=\{\mathrm{x}: \mathrm{x} \in \mathrm{L}(\mathrm{y}), \theta \mathrm{x} \in \mathrm{L}(\mathrm{y}), \theta \notin(0,1)\}, \mathrm{y}$ $\in \mathrm{R}^{\mathrm{M}}$. Also corresponding to the GR of the technology is a family of output sets $\mathrm{P}(\mathrm{x})=\{\mathrm{y}:(\mathrm{y}, \mathrm{x}) \in \mathrm{GR}\}, \mathrm{x} \in \mathrm{R}^{\mathrm{N}}{ }_{+}$. Output sets are assumed to be closed and bounded above, and to satisfy the properties of convexity and strong disposability of outputs. A Farrell - Debreu radial measure of the technical efficiency of input vector $\mathrm{x}$ in the production of output vector $\mathrm{y}$ is given by: $\mathrm{TE}(\mathrm{x}, \mathrm{y})=\min \{\theta: \theta \mathrm{x} \in \mathrm{L}(\mathrm{y})\}$, where $\theta=1$ indicates radial technical efficiency and $\theta<1$ shows the degree of radial technical inefficiency.

Variable return to scale (VRS) hypothesis has been used and the linear programming is described as follows: Suppose there are $\mathrm{p}$ inputs and $\mathrm{q}$ outputs for $\mathrm{n}$ clinics DMUs. For the $i$-th clinics DMUs, $y_{i}$ is the column vector of the outputs and $\mathrm{x}_{\mathrm{i}}$ is the column vector of the inputs. Also it can be defined $\mathrm{X}$ as the $\left(p^{*} n\right)$ input matrix and $Y$ as the $\left(q^{*} n\right)$ output matrix. Then the DEA model for a given i-th clinic DMU is specified with the following mathematical programming problem:

$\max _{\lambda, \delta \mathrm{i}} \delta_{\mathrm{i}}$

subject to $\delta_{i} y_{i} \leq Y_{\lambda}$

$\mathrm{x}_{\mathrm{i}} \geq \mathrm{X}_{\lambda}$

nl' $\lambda=1$

$\lambda \geq 0$

In the above expression (1), $\delta_{\mathrm{i}}$ is a scalar satisfying $\delta_{\mathrm{i}} \geq 1$. It is the efficient score that measures technical efficiency of the i-th clinic as the distance to the efficiency frontier, the latter being defined as a linear combination of best practice observations. With $\delta_{\mathrm{i}}>1$, the decision unit is inside the frontier (i.e. it is inefficient), while $\delta_{i}=1$ implies that the decision unit is on the frontier (i.e. it is efficient). The vector $\lambda$ is a $\left(n^{*} 1\right)$ vector of constrains that measures the weights used to compute the location of an inefficient DMU if it were to become efficient.

This study considers hospitals as a multi-product organisation and their clinics producing two outputs (number of in-patients treated and inpatient days), and having four different inputs (doctors, registrars doctors, nurses, beds). The annual number of full-time staff employed in each clinic 
was used as labour inputs and the number of beds as an aggregate proxy of capital inputs.

The RHAT includes four prefectures in which five (5) hospitals operate; the University District Hospital (UDH-708 beds) and the General Hospital (GH 405 beds) in the prefecture of Larissa, the GH in the prefecture of Volos ( 400 beds), the GH in the prefecture of Trikala (320 beds) and the GH in the prefecture of Karditsa (300 beds). Data were obtained from each hospital records per clinic for the years 2002-2006 and refer to all major acute medical and surgical specialities. All hospitals and clinics taken into consideration belong to the National Health System (NHS) and provide acute secondary care. Thus, university hospital clinics and intensive care units (ICU) are excluded from the analysis, due to the different service-mix [67]. Additionally, outpatient care including laboratory examinations and day care services provided by all hospitals are also excluded in order to increase the homogeneity of outputs. The numbering of the hospitals (as presented in the tables) is: 1- UDH of Larissa, 2- GH of Larisa, 3- GH of Volos, 4- GH of Karditsa, 5- GH of Trikala. The study uses the Regional Health Authority (RHA) perspective.

The model is run for both CRS and VRS. Each hospital clinic is considered to be a single DMU in terms of specialty and provision of in-patient care. In order to create comparable units and avoid heterogeneity of the sample, two separate DEA models were built. Both models take separately into account two subsets, namely the GM DMUs (B1) and the surgical DMUs (B2). The GM DMUs (B1) includes GM (MED01) clinics. Additionally, the surgical DMUs include gynaecology (SUR01), ophthalmology (SUR02), orthopaedics (SUR03), urology (SUR04), paediatrics surgery (SUR05) and general surgery (SUR06) clinics. Each subset has been performed separately on two groups of homogeneous clinics. Homogeneous DMUs are considered as the same GM and surgical specialties operating across the five hospitals of the region for all the years under study. Thus, the data that underpins our DEA analysis comprised of a total of 175 DMUs, composed of 25 homogeneous GM clinics and 150 homogenous surgical clinics. The number of hospital beds in each clinic varies in accordance to the process of hospital planning totalling in 1,282 beds in 2006. The total number of medical staff working at the homogeneous clinics was 525 in 2006, while the nursing staff was almost double. In our model and for the above-mentioned homogeneous DMUs (clinics), the number of annual full-time staff employed in each clinic and beds have been used as labour and capital inputs respectively. Also, the annual number of inpatients treated and inpatient days have been used as the produced outputs. In 2006 the number of patient treated in the homogenous clinics of the region accounted for 108.573 and the inpatient days for 352.488 .

DEA models for the GM and the surgical DMUs were evaluated in terms of their across hospital performance over the period 2002-2006. The results were obtained using "DEA.P Version 2.1 for windows" by Coelli (1996c) and the XLDEA $2010[18,74]$.

\section{RESULTS}

In this paper, hospital performance has been assessed by measuring homogenous clinics' efficiency through a set of similar DMUs. DEA efficiency scores at clinical level, as presented in our results, are related to the relative efficiency of the services provided by each clinic or to inefficiencies related to the excessive and incorrect input utilisation. Fully efficient clinics per hospital and per year are those which scored 1.00 and achieved the highest performance, $100 \%$ efficiency scores. Inefficiency or minimum levels of performance refer to any regressed scores below 1.00 or below $100 \%$ efficiency scores.

DEA efficiency scores of the homogeneous DMUs are analytically presented in the Tables $\mathbf{1}$ and $\mathbf{2}$ for the years 2002-2006. In GM clinics (Table 1), it is observed that $100 \%$ efficiency scores were achieved only by the UDH (1) overtime. The GH of Larisa (2) and the GH of Volos (3), although fully efficient for the first three years, appear slightly inefficient in 2006 and 2005-2006 respectively. GH of Karditsa (4) and Trikala (5) did not achieve high levels of performance.

According to the Table 2 data, it is observed that only 2 homogeneous surgical clinics scored overtime $100 \%$ efficiency, the ophthalmology (SUR02) from the GH of Larisa (2) and the urology (SUR04) from the GH of Karditsa (5). The aforementioned clinics achieved the highest efficiency scores across all the hospitals overtime, except the UDH of Larisa (1).

In addition, according to the Tables $\mathbf{1}$ and $\mathbf{2}$, mean efficiency scores did not show significant difference assuming either VRS or CRS. More analytically, in 2002 the scores were under VRS: 0,89 and CRS: 0,87, in 2003: 0,93 and 0,90; in 2004: 0,86 and 084; in 2005: 0,81 and 0,79; in 2006: 0,87 and 0,84 respectively. Furthermore, both homogeneous clinics groups (GM and surgical) followed similar trends in the curves, as presented in the Figs ( 1 and 2), with the mean efficiency scores during the years 20022006 ranging for the GM from 0,81 to 0,98 under VRS and from 0,79 to 0,90 under CRS. Also, mean efficiency scores for the surgical clinics ranged from 0,73 to 0,94 under VRS and from 0,69 to 0,79 under CRS (Tables 1 and 2).

The choice of using both CRS and VRS relies on the analysts' understanding of the hospital sector, showing that technology might vary in the hospitals' clinics and operations might lead to inefficiencies.

If the CRS technology is inappropriately applied when, say, all hospitals are operating at a sub-optimal scale, then the estimates of technical efficiency will be confounded by scale efficiency effects. To calculate scale inefficiency, both the CRS and VRS DEA models are run on the same data, and any change in measured efficiency can be attributed to the presence of scale inefficiency.

The curves in Figs (1 and 2) show that both CRS and VRS mean efficiency scores follow parallel efficiency flows 
Table 1. Efficiency Scores Among Homogeneous Clinics* in GM (B1).

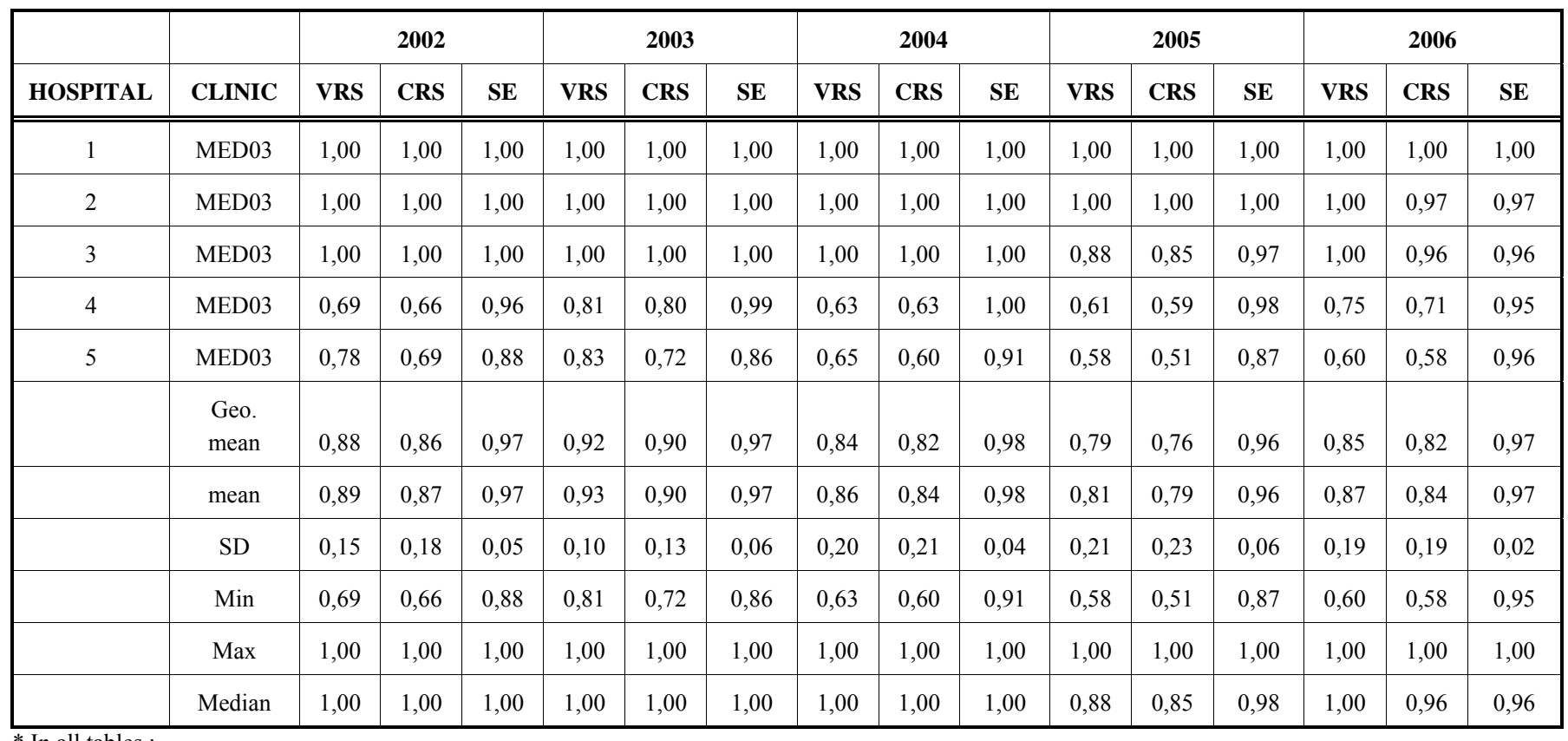

* In all tables :

- numbering stands for : 1 - UDH of Larisa, 2- GH of Larisa 3 - GH of Volos, 4 - GH of Karditsa, 5 - GH of Trikala

- $\quad$ VRS - variable returns to scale, CRS - constant returns to scale, SE - scale efficiency

- $\quad$ MED stands for the GM clinics and SUR for the surgery clinics

Table 2. Efficiency scores among homogeneous surgical clinics* (B2)

\begin{tabular}{|c|c|c|c|c|c|c|c|c|c|c|c|c|c|c|c|c|}
\hline HOSPITAL & CLINIC & \multicolumn{3}{|c|}{2002} & \multicolumn{3}{|c|}{2003} & \multicolumn{3}{|c|}{2004} & \multicolumn{3}{|c|}{2005} & \multicolumn{3}{|c|}{2006} \\
\hline 1 & SUR02 & 0,25 & 0,25 & 0,98 & 0,45 & 0,45 & 0,99 & 0,44 & 0,44 & 1,00 & 0,36 & 0,35 & 0,99 & 0,39 & 0,36 & 0,92 \\
\hline 1 & SUR03 & 1,00 & 0,98 & 0,98 & 1,00 & 0,97 & 0,97 & 0,63 & 0,59 & 0,93 & 0,81 & 0,74 & 0,92 & 0,83 & 0,82 & 0,99 \\
\hline 1 & SUR05 & 0,62 & 0,54 & 0,87 & 1,00 & 0,97 & 0,97 & 0,73 & 0,69 & 0,93 & 0,85 & 0,74 & 0,87 & 1,00 & 0,98 & 0,98 \\
\hline 1 & SUR06 & 0,90 & 0,83 & 0,92 & 1,00 & 1,00 & 1,00 & 0,98 & 0,96 & 0,98 & 0,77 & 0,77 & 1,00 & 0,83 & 0,76 & 0,92 \\
\hline 2 & SUR01 & 0,48 & 0,44 & 0,93 & 0,53 & 0,50 & 0,95 & 0,42 & 0,41 & 0,98 & 0,43 & 0,37 & 0,87 & 0,58 & 0,48 & 0,82 \\
\hline 2 & SUR05 & 0,56 & 0,53 & 0,94 & 0,66 & 0,66 & 1,00 & 0,54 & 0,52 & 0,96 & 0,48 & 0,48 & 1,00 & 0,79 & 0,71 & 0,90 \\
\hline 2 & SUR06 & 0,63 & 0,62 & 0,98 & 0,77 & 0,75 & 0,97 & 0,61 & 0,60 & 0,98 & 0,69 & 0,68 & 0,99 & 0,86 & 0,82 & 0,95 \\
\hline 3 & SUR01 & 0,70 & 0,61 & 0,88 & 0,84 & 0,71 & 0,84 & 0,66 & 0,59 & 0,89 & 0,49 & 0,49 & 1,00 & 0,64 & 0,64 & 1,00 \\
\hline 3 & SUR02 & 1,00 & 0,50 & 0,50 & 1,00 & 0,59 & 0,59 & 0,49 & 0,49 & 1,00 & 0,48 & 0,31 & 0,64 & 1,00 & 0,31 & 0,31 \\
\hline 3 & SUR03 & 1,00 & 1,00 & 1,00 & 1,00 & 1,00 & 1,00 & 0,92 & 0,89 & 0,96 & 0,89 & 0,89 & 1,00 & 1,00 & 1,00 & 1,00 \\
\hline 3 & SUR04 & 1,00 & 1,00 & 1,00 & 1,00 & 1,00 & 1,00 & 1,00 & 1,00 & 1,00 & 1,00 & 1,00 & 1,00 & 1,00 & 0,97 & 0,97 \\
\hline 3 & SUR05 & 0,74 & 0,65 & 0,88 & 0,69 & 0,61 & 0,89 & 0,68 & 0,63 & 0,93 & 0,60 & 0,57 & 0,94 & 0,58 & 0,56 & 0,98 \\
\hline
\end{tabular}


Table 2. Contd.....

\begin{tabular}{|c|c|c|c|c|c|c|c|c|c|c|c|c|c|c|c|c|}
\hline HOSPITAL & CLINIC & \multicolumn{3}{|c|}{2002} & \multicolumn{3}{|c|}{2003} & \multicolumn{3}{|c|}{2004} & \multicolumn{3}{|c|}{2005} & \multicolumn{3}{|c|}{2006} \\
\hline 4 & SUR01 & 1,00 & 0,42 & 0,42 & 1,00 & 0,67 & 0,67 & 1,00 & 0,58 & 0,58 & 0,47 & 0,45 & 0,96 & 0,70 & 0,36 & 0,51 \\
\hline 4 & SUR02 & 1,00 & 0,69 & 0,69 & 1,00 & 1,00 & 1,00 & 1,00 & 0,81 & 0,81 & 0,71 & 0,70 & 0,98 & 0,84 & 0,83 & 0,99 \\
\hline 4 & SUR04 & 1,00 & 1,00 & 1,00 & 1,00 & 1,00 & 1,00 & 1,00 & 1,00 & 1,00 & 1,00 & 0,99 & 0,99 & 1,00 & 1,00 & 1,00 \\
\hline 4 & SUR05 & 0,69 & 0,65 & 0,95 & 0,89 & 0,89 & 1,00 & 0,83 & 0,81 & 0,98 & 0,63 & 0,61 & 0,96 & 0,76 & 0,76 & 0,99 \\
\hline 4 & SUR06 & 0,58 & 0,56 & 0,97 & 0,80 & 0,62 & 0,77 & 0,54 & 0,53 & 0,96 & 0,42 & 0,41 & 0,97 & 0,52 & 0,50 & 0,98 \\
\hline 5 & SUR04 & 1,00 & 1,00 & 1,00 & 1,00 & 1,00 & 1,00 & 1,00 & 1,00 & 1,00 & 1,00 & 1,00 & 1,00 & 1,00 & 1,00 & 1,00 \\
\hline 5 & SUR05 & 0,52 & 0,46 & 0,90 & 0,55 & 0,52 & 0,95 & 0,39 & 0,39 & 0,99 & 0,35 & 0,30 & 0,86 & 0,47 & 0,43 & 0,91 \\
\hline \multirow[t]{5}{*}{5} & SUR06 & 0,80 & 0,68 & 0,86 & 0,73 & 0,67 & 0,93 & 0,61 & 0,54 & 0,89 & 0,58 & 0,49 & 0,84 & 0,49 & 0,44 & 0,90 \\
\hline & Geo. Mean & 0,76 & 0,66 & 0,86 & 0,84 & 0,76 & 0,90 & 0,76 & 0,70 & 0,93 & 0,70 & 0,65 & 0,94 & 0,79 & 0,71 & 0,90 \\
\hline & Mean & 0,80 & 0,70 & 0,88 & 0,86 & 0,79 & 0,91 & 0,79 & 0,73 & 0,94 & 0,73 & 0,69 & 0,94 & 0,82 & 0,75 & 0,92 \\
\hline & SD & 0,24 & 0,23 & 0,17 & 0,18 & 0,20 & 0,13 & 0,22 & 0,21 & 0,11 & 0,23 & 0,23 & 0,09 & 0,19 & 0,22 & 0,15 \\
\hline & Min & 0,25 & 0,25 & 0,42 & 0,45 & 0,45 & 0,51 & 0,39 & 0,39 & 0,58 & 0,35 & 0,30 & 0,64 & 0,39 & 0,31 & 0,31 \\
\hline
\end{tabular}

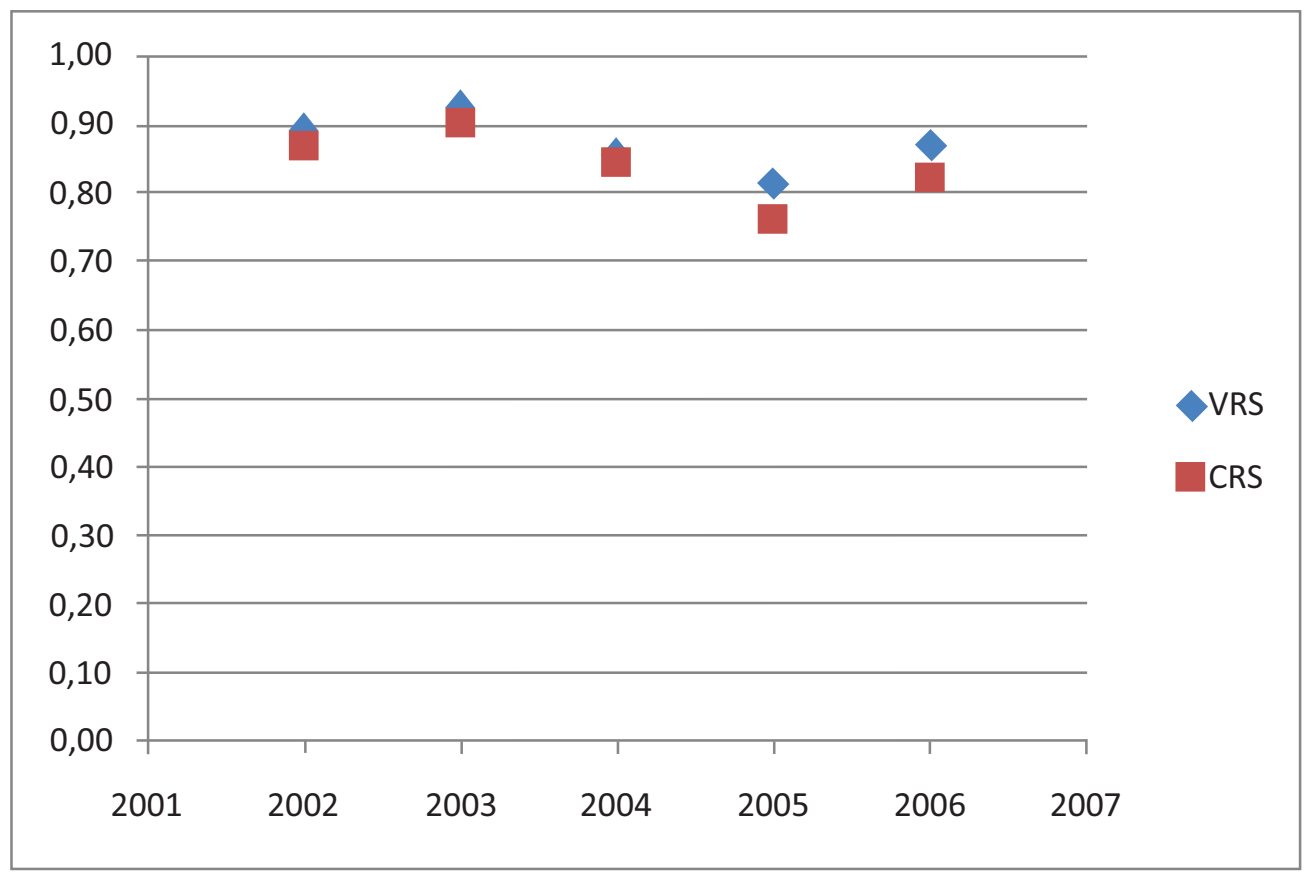

Fig. (1). Mean efficiency scores for the homogeneous GM clinics under VRS and CRS. 
with comparable data results. To produce more comparable results, both figures show that homogenous surgical as GM clinics achieved the highest efficiency scores in 2003 while inefficiencies appeared in 2005 . The data supporting these indicators are extracted from the Tables $\mathbf{1}$ and $\mathbf{2}$.

Extracting the fully efficient DMUs (Table 3) from the homogeneous clinics including both GM (B1) and surgical clinics (B2) diachronically, it appears that 74 DMUs under VRS and 47 DMUs under CRS were fully efficient, accounting for $42 \%$ and $27 \%$ of the total sample (175 DMUs) respectively. Taking into consideration the homogeneous clinics under both VRS and CRS that diachronically remained fully efficient (Table 4), it is shown that five (5) GM and ten (10) surgical DMUs performed efficiently. Moreover, total mean efficiency scores of the GM clinics

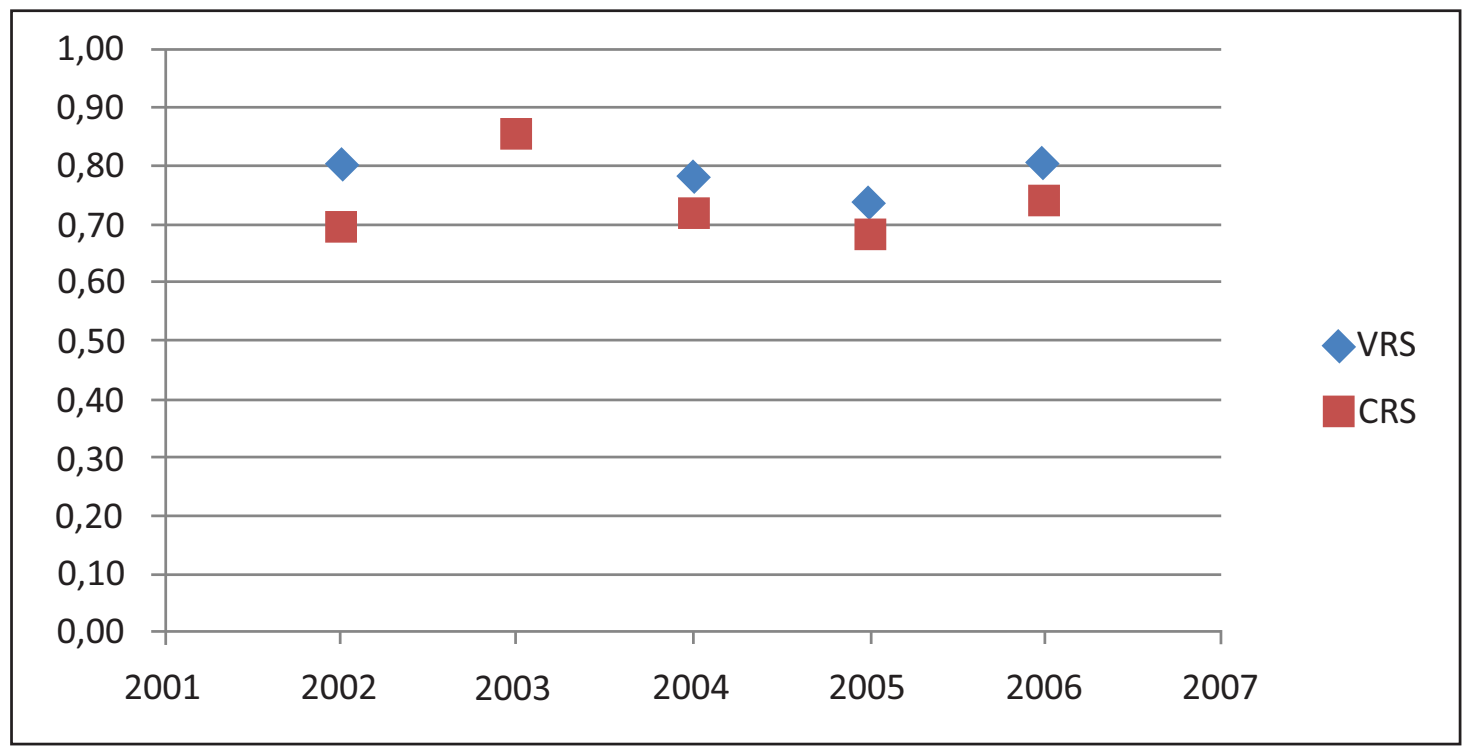

Fig. (2). Mean efficiency scores for the homogeneous surgical clinics under VRS and CRS.

Table 3. Fully Efficient Homogeneous Clinics Overtime (in Absolute Numbers).

\begin{tabular}{|c|c|c|c|c|c|}
\hline & $\begin{array}{c}\text { Fully efficient GM clinics } \\
\text { (B1) }\end{array}$ & \multicolumn{2}{c|}{$\begin{array}{c}\text { Fully efficient surgical clinics } \\
\text { (B2) }\end{array}$} & $\begin{array}{c}\text { Total fully efficient clinics (B1 + } \\
\text { B2) }\end{array}$ \\
\hline \hline & VRS** & CRS & VRS & CRS & VRS \\
\hline Total homogeneous DMUs* & 14 & 11 & 60 & 36 & 74 \\
\hline & & & & & \\
\hline
\end{tabular}

*DMUs - Decision Making Units

**VRS - variable returns to scale, CRS - constant returns to scale.

Table 4. Fully Efficient Clinics Overtime

\begin{tabular}{|c|c|c|c|c|c|c|c|c|c|c|c|}
\hline \multicolumn{4}{|c|}{ VRS 2002-2006 } & \multicolumn{4}{|c|}{ CRS 2002-2006 } & \multicolumn{4}{|c|}{ VRS + CRS 2002-2006 } \\
\hline \multicolumn{2}{|c|}{ GM clinics (B1) } & \multicolumn{2}{|c|}{ Surgery clinics (B2) } & \multicolumn{2}{|c|}{ GM clinics (B1) } & \multicolumn{2}{|c|}{ Surgery clinics (B2) } & \multicolumn{2}{|c|}{ GM clinics (B1) } & \multicolumn{2}{|c|}{ Surgery clinics (B2) } \\
\hline 1 & MED03 & 2 & SUR04 & 1 & MED03 & 2 & SUR04 & 1 & MED03 & 2 & SUR04 \\
\hline 2 & MED03 & 3 & SUR07 & & & 5 & SUR07 & & & 5 & SUR07 \\
\hline \multirow[t]{4}{*}{3} & MED03 & 3 & SUR09 & & & & & & & & \\
\hline & & 4 & SUR07 & & & & & & & & \\
\hline & & 5 & SUR04 & & & & & & & & \\
\hline & & 5 & SUR07 & & & & & & & & \\
\hline Total & 15 & & 30 & & 5 & & 10 & & 5 & & 10 \\
\hline
\end{tabular}

- Numbering stands for : 1 - UDH of Larissa, 2- GH of Larissa, 3 - GH of Volos, 4 - GH of Karditsa, 5 - GH of Trikala,

- MED stands for the general medicine clinics and SUR for the surgery clinics.

- $\quad$ VRS - variable returns to scale, CRS - constant returns to scale. 
Table 5. Total Mean Efficiency Scores Overtime

\begin{tabular}{|c|c|c|}
\hline & \multicolumn{2}{|c|}{ Homogeneous Clinics* } \\
\hline & VRS & CRS \\
\hline \hline GM Clinics & 0,89 & 0,85 \\
\hline Surgery Clinics & 0,80 & 0,77 \\
\hline
\end{tabular}

* VRS - variable returns to scale, CRS - constant returns to scale.

were higher (VRS: 0,89 - CRS: 0,85) than the surgical (VRS: 0,80 - CRS: 0,73) under both VRS and CRS (Table 5). Also, they present similar mean efficiency scores which vary from $80 \%$ to $90 \%$.

\section{DISCUSSION}

Health care budgets in almost all the EU Member States are under pressure due to the continuous increase in patients' expectations, health technologies and related costs together with the population ageing. The use of alternative managerial techniques, such as DEA, tend to attract mounting interest in the economics of the health care sector. DEA analysis has been widely used in other economic sectors since 1957 as organisations have struggled to improve productivity and efficiency. Farell in his classic paper [13] stated the reason that is important to focus on measuring efficiency and productivity. After Farells' seminal work many researchers responded to the need for satisfactory procedures in measuring efficiency and come up with methodological developments in several sectors [1,2,8-12,14-34].

Seeing the necessity for comparative assessment in the NHS hospitals, we decided to carry out this research at the public hospitals of the region of Thessaly. Therefore, the aim of the paper was to assess hospital performance among homogeneous clinics in the specific region by using output oriented DEA, over the period 2002-2006. A two model analysis has been adapted in order to create two groups of homogeneous clinics in terms of GM and surgical specialties. The results show that GM clinics present higher efficiency than the surgical ones overtime. Both clinics' groups present a similar path of VRS and CRS in terms of longitudinal efficiency. In particular, it has been observed that in the years 2002 and 2006 both GM and surgical clinics show similar results. In 2003 the majority of the clinics achieved the highest efficiency scores, while in 2005 they achieved a minimum level of performance. The high efficiency scores observed in 2003 seem to be adjusted to the reform introduced in 2001 (law 2889/2001) regarding the decentralisation of the NHS and the establishment of seventeen (17) RHAs in the country. This reform had a positive effect on the performance of the clinics in the specific region, since decision-making followed local population needs and characteristics. However, the regress in efficiency gains of specific clinics in 2005 seems to be affected by the introduction of a new law (3329/2005), which reduced RHA from seventeen (17) to seven (7). This law, which was introduced without any regard to the local needs, performance indicators and other regional socioeconomic characteristics, has resulted in the expansion of RHA responsibilities in the provision of healthcare. At this point, it should be noted that there are no regulatory restrictions regarding patient choice of the clinics/hospitals related to patient residence in all the RHA of the country. In addition, hospital managers have limited incentives to put emphasis on the efficiency and productivity issues, as the planning side of the hospitals is beyond their responsibilities and it depends on the government.

The results of this study indicate hospital inefficiencies among GM and surgical homogeneous clinics per year and diachronically in the RHAT. It should be mentioned that the findings present similarities to the results of other studies, already reported in the international literature. Most of the studies reveal inefficiencies related to the structural, organisational and managerial performance of the hospitals $[35,38,40-44,48-51,53,55,59-63]$ and report similar mean efficiency scores which vary from $80 \%$ to $90 \%[8,47-50$, $55-58,61,75-86]$. Differences in the efficiency rates from year to year among German and Swiss hospitals are also reported in a study [84]. In addition, studies comparing the efficiency among homogeneous specialty clinics have been conducted in Austria, Norway and in Italy $[38,40,50,52,53]$. The efficiency measurement of these studies included clinics of big, medium and small size hospitals $[38,40,50,52,53]$. The results showed that small size hospitals-in terms of beds- as well as clinics with complex cases had lower efficiency rates [38, 40]. Having used almost the same methodology with the above studies, it is observed that our results are similar. The size of the hospitals -in terms of beds- influences efficiency. More specifically, the GM clinics of the UDH of Larissa, the biggest hospital in the region, had the highest efficiency scores. Adversely, in specific surgical clinics it seems that the size of the hospitals does not influence efficiency, since the UDH of Larissa appeared less efficient that the smaller ones. Adversely, in specific surgical clinics it seems that the size of the hospitals does not influence efficiency, since the UDH of Larissa appeared less efficient that the smaller ones. The lower efficiency scores of the specific hospital may be due to the fact that patients prefer the university's surgical clinics instead of the NHS' ones. At this point, it should be mentioned that university clinics are excluded from the analysis, since they provide tertiary care and do not belong to the NHS hospitals. However, our finding that surgical clinics have lower efficiency scores than the general clinics may be due to the fact that they treat more complex cases, as already reported in the international literature [38, 40]. Moreover, both the effect of the reforms regarding the restructuring of the RHAT as well as the organisation and management of the hospitals have also been reported in a study [38]. Furthermore, similar DEA efficiency results ranging from $83 \%$ to $90 \%$ for the years $1998-2005$ as well as differences in efficiency scores per year have been reported in a study conducted in another RHA in Greece [43].

In an era of economic recession, the assessment of hospital efficiency and productive performance can be of great value at the micro level in order to compare clinics across different hospitals. The link between healthcare, costs and efficiency is particularly crucial in the context of defining new areas of potential national action. DEA is a useful tool for measuring homogeneous clinics' and hospitals' performance at national and/or regional level. 
Furthermore, it would be interesting to investigate DEA as a tool for measuring performance at a clinical level. Putting an increased emphasis on targeted investments in health, it is essential to ensure complementarity of efficient activities of hospital clinics and also other health care settings. With this particular view, DEA methodology has been used to measure efficiency in hospitals $[4,8,30,34,36-39,42-50,53-60,64,65$, $75-86]$, in health care systems $[5,6,32,33,35,41,63,66,68]$, in primary care [7], in clinical departments $[38,40,50-53]$, in specialized units / laboratory $[61,62]$ and in physicians activities [51]. Therefore, a best practice mechanism at national level such as DEA methodology, could be established to identify, validate and disseminate good practices and information on policies, interventions and actions which lead to greater efficiency, including the development of quality control instruments, supporting evidence and long-term benefits.

Despite the fact that this is the first empirical attempt to measure efficiency among homogeneous specialty clinics across hospitals in a specific region in Greece, it should be mentioned that there are strengths and weaknesses in this study. An important methodological advantage is that the assessment of hospitals' performance is focused on homogeneous specialties. Additionally, the regional perspective taken into consideration constitutes another advantage since the socio-demographic and epidemiological profile of the RHAT population is mostly the same. Additional strength of the methodology used is that the output - oriented DEA model is considered the most appropriate because it addresses ways of efficient use of resources that maximise hospital outputs with the minimum use of inputs, given the financial and labour restrictions imposed by the IMF and the $\mathrm{EU}[70]$.

There are also methodological limitations that should be mentioned. Although our results indicate NHS hospitals' performance inefficiencies, as elsewhere in the Greek literature $[35,41,43-49,54,55]$, the sample selection limits the generalisation of our results across the country. However, the absence of a hospital integrated electronic registering and monitoring system, providing national data and related costs, does not provide the opportunity to compare data at a national level and measure allocative efficiency. Thus, the fact that our DEA analysis is based on analytical clinical data of the specific region, overtime, can be considered as an additional advantage. Finally, the data set used does not reflect outcomes' quality assessment adjusted for case-mix and in-patients severity due to unavailability of relevant sources.

According to our analysis, it appears that the decentralization of the NHS had a positive impact on hospital performance of the specific region, since decisionmaking is facilitated at the local level. However, political pressure overtime has resulted in a series of reforms in the country, which did not take into consideration neither the social nor the economic environment of each region. This kind of intervention constitutes the major barrier in both health policy decision-making and resources' allocation. Obviously, the maintenance of this situation underestimates the "equity", "accessibility" and "quality" criteria, which constitute the institutional principles and patient rights of the NHS law in Greece.

In this study we concluded that DEA is a useful tool for measuring homogeneous clinics' and hospitals' performance at national and/or regional level. Furthermore, it would be interesting to investigate DEA as a tool for measuring performance among heterogeneous clinics or secondary and tertiary hospitals. Policy makers should consider the results of such studies and move forward with decision-making based on hospital efficiency measurements. Consequently, health reforms which take into consideration evidence-based practices may lead to intra and across hospital collaborations as well as to the merging of inefficient clinics; this way economies of scale, and therefore potential savings in the hospital sector, could be achieved.

\section{CONCLUSION}

The introduction of DEA as a practical research tool for examining efficiency across hospital clinics in Greece opens a path to evaluate and compare hospital performance. Performance assessment of homogeneous specialty clinics showed that some clinics appear to be operating relatively more efficiently than others. The adoption of hospital performance assessment techniques will integrate efficiency measures into decision-making and improve priority setting. The economic crisis Greece is facing at this time necessitates the incorporation of NHS hospitals' performance assessment.

\section{CONFLICTS OF INTEREST}

The authors confirm that this article content has no conflicts of interest.

\section{ACKNOWLEDGEMENTS}

The authors wish to thank Mr. Nikos Kotsopoulos health economist for his valuable help regarding the identification of key issues in the application of the DEA.

\section{REFERENCES}

[1] Worthington AC. Frontier efficiency measurement in health care: a review of empirical techniques and selected applications. Med Care Res Rev 2004; 61(4): 135-70.

[2] Grosskopf S. Efficiency and productivity. In: Fried HO, Lovell CAK, Schmidt SS, Eds. The measurement of productive efficiency: techniques and applications. New York: Oxford University Press 1993; pp. 161-94.

[3] Riseborough PA, Walter M. Management in Health Care. Wright: London 1988.

[4] Schulz R, Johnson A. Management of hospital and health service. Strategic issues and performance. USA: Mosby Co 1990.

[5] Folland S, Goodman A, Stano M. The economics of health and health care. USA: Pearson Prentice Hall 2004.

[6] Paci P, Wagstaff A. Equity and efficiency in Italian health care. Health Econ 1993; 2(1):15-29.

[7] Marschall P, Flessa S. Efficiency of primary care in rural Burkina Faso. a two stage DEA analysis. Health Econ Rev 2011; 1: 5.

[8] Sherman D. Hospital efficiency measurement and evaluation empirical test of a new technique H. DBA 1984; 22(10): 922-38.

[9] Caves DW, Christensen LR, Diewert WE. The economic theory of index numbers and measurement of input, output and productivity. Econometrica 1982; 50(6): 1393-414. 
[10] Bunker RD, Charnes A, Cooper WW. Some models for estimation of technical and scale efficiencies in data envelopment analysis. Man Sci 1984; 30(10):1078-92.

[11] Lovell CAK. Production frontiers and productive efficiency in the measurement of productive efficiency: Techniques and applications. In: Fried HO, Lovell CAK, Schmidt SS, Eds. The measurement of productive efficiency: techniques and applications. New York: Oxford University Press 1993.

[12] Lovell CAK. Applying efficiency measurement techniques to the measurement of productivity. J Prod An 1996; 7(2-3): 329-40.

[13] Farrell MJ. The measurement of productive efficiency. J Royal Stat Soc 1957; 120(3): 153-281.

[14] Cook W, Seiford L. Data envelopment analysis (DEA) - thirty years on. Eur J Op Res 2009;192(1):1-17.

[15] Charnes A, Cooper WW, Rhodes E. Measuring efficiency of decision-making units. Eur J Op Res 1978; 2(6):429-44.

[16] Newhouse JP. Frontier estimation: how useful a tool for health economics? J Health Econ 1994; 13(3): 317-22.

[17] Färe R, Grosskopf S, Lovell CAK. Production frontiers. Production Frontiers. Cambridge: Cambridge University Press 1994a.

[18] Coelli T. A guide to DEAP version 2.1: a data envelopment analysis (computer) program. center for efficiency and productivity analysis. University of New England. CEPA Working 1996c; Papers No.08/96. ISSN 1327-435X. ISBN 1 86389 4969; 96/08.

[19] Coelli T, Rao DSP, Battase GE. An introduction to efficiency and productivity analysis. Boston: Kluwer 1998.

[20] Coelli TJ, Perelman S. Comparison of parametric and nonparametric distance functions: with application to European railways. CREPP Discussion paper. Liege: University of Liege 1996a; pp. 96-1011.

[21] Coelli TJ, Perelman S. Efficiency measurement, multiple-output technologies and distance functions: With application to European railways. CREPP Discussion paper. Liege: University of Liege 1996b; pp. 96-05.

[22] Charnes A, Cooper W, Lewin AY, Seiford LM. Data envelopment analysis: Theory, methodology and applications. Boston: Kluwer 1994.

[23] Norman M, Stoker B. Data envelopment analysis: The assessment of performance. Chichester: Wiley 1991.

[24] Färe R, Grosskopf, S, Norris M, Zhang Z. Productivity growth, technical progress, and efficiency change in industrialized countries. Am Econ Rev 1994b; 84(1): 66-83.

[25] Färe R, Primont D. Multi-output production and duality: theory and applications. Boston: Kruwer 1995.

[26] Fried H, Lovell CAK, Schmidt S. The measurement of productive efficiency. New York: Oxford University Press 1993.

[27] Thanassoulis E. Introduction to the theory and application of data envelopment analysis. Boston: Kluwer 2004.

[28] Cooper WW, Seiford LM, Thanassoulis E, Zanakis SH. DEA and its use in different countries. Eur J Open Res 2004; 154(2): 337-44.

[29] Cooper WW, Seiford LM, Tone K. Introduction to data envelopment analysis and its uses. US: Springer Sci 2006; p. 351.

[30] Färe R, Grosskopf S, Lindgren B, Proos P. Productivity development in Swedish hospitals: a malmquist output index approach. Southern Illinois University, Carbondale. department of economics discussion paper; 1989a:No 89-3. In: Charnes A, Cooper WW, Lewin AY, Seiford LS, Eds. Data envelopment analysis: theory, methodology and applications. Amsterdam: Kluwer 1995.

[31] Palmer S, Torgerson DJ. Definitions of efficiency. Br Med J 1999; 318 (7191): 1136 .

[32] Hollingsworth B. Non-parametric and parametric applications measuring efficiency in health care. Health Care Man Sci 2003; 6(4): 203-18.

[33] Hollingsworth B, Dawson P, Maniadakis N. Efficiency measurement of health care: a review of non-parametric methods and applications. Health Care Man Sci 1999; 2(3): 161-72.

[34] Färe R, Grosskopf S, Valdmanis V. Capacity, competition and efficiency in hospitals: a nonparametric approach. J Prod An 1989;1: 123-38.

[35] Halkos G, Tzeremes N. A conditional non-parametric analysis for measuring the efficiency of regional public healthcare delivery. Health Policy 2010; 1010/6: 10021.

[36] Polyzos NM. Striving towards efficiency in the Greek hospitals by reviewing case mix classifications. Health Policy 2002; 61(3): 30528.
[37] Chirikos TN, Sear AM. Measuring hospital efficiency: a comparison of two approaches. HRS: Health Serv Res 2000; 34 (6): $1389-408$

[38] Ancarani A, Mauro C Di, Giammanco MD. The impact of managerial and organizational aspects on hospital wards' efficiency: evidence from a case study. Eur J Open Res 2009; 194: 280-93.

[39] Steinmann L, Zweifel P. On the (in)efficiency of Swiss hospitals. Appl Econ 2003; 35:361-70.

[40] Magnusen J, Nyland K. Measuring efficiency in clinical departments. Health Policy 2008; 87: 1-7.

[41] Maniadakis N, Thanassoulis E. A cost malmquist productivity index. Special issue: DEA and its uses in different countries. Eur J Open Res 2004; 154(2): 396-409.

[42] Steinmann L, Zweifel P. Zur, In: Effizienzscweizerisher Krankenhauser. On the inefficiencies of Swiss hospitals. (With English summary) Ifo Studien 2000; 46: 197-217.

[43] Prezerakos P, Maniadakis N, Kaitelidou D, Kotsopoulos N, Yfantopoulos J. Measuring across hospital efficiency and productivity: the case of second regional health suthority of Attica. Eur Res Stud 2007; X(1-2):83-96.

[44] Maniadakis N, Kotsopoulos N, Prezerakos P, Yfantopoulos J. Measuring intra-hospital clinic efficiency and productivity: application to a Greek university general hospital. Eur Res Stud 2007; XI(1-2): 95-110.

[45] Maniadakis N, Hollingsworth B, Thanassoulis E. The impact of the internal market on hospital efficiency productivity and service quality. Health Care Man Sci 1999; 2: 75-85.

[46] Maniadakis N, Thanassoulis E. Assessing productivity changes in UK hospitals reflecting technology and input prices. Appl Econ 2000; 32(12): 1575-89.

[47] Giokas DI. Greek hospitals: how well their resources are used. Omega 2001; 29(1):73-83.

[48] Athanassopoulos AD, Gounaris C. Assessing the technical and allocative of hospital allocations in Greece and its resource allocation implications. Eur J Open Res 2001; 133(2): 416-31.

[49] Athanassopoulos AD, Gounaris C, Sissouras A. A descriptive assessment of the production and cost efficiency of general hospitals in Greece. Health Care Man Sci J 1999; 2 (2): 97-106.

[50] Hofmarcher MM, Paterson I, Riedel M. Measuring hospital efficiency in Austria - a DEA approach. Health Care Man Sci 2002; 5 (1): 7-14.

[51] Chilingerian JA. Evaluating physician efficiency in hospitals: a multivariate analysis of best practices. Eur J Open Res 1995; 80: 548-74.

[52] Testi A. Misure dellefficienza tecnica e di scala dei servizi ospedalieri. In: Rapporto Sanita. Franco Angeli, Milano 2000.

[53] Rosko M, Chilingerian JA. Estimating hospital inefficiency: Does case mix matter? J Med Sys 1999; 23: 57-71.

[54] Yfantopoulos J. Fixed proportion production model for hospitals. Socio-Economic Planning; Great Britain: Pergamon Press Ltd 1980; vol. 14: pp. 193-5.

[55] Aletras V. A comparison of hospital scale effects in short-run and long-run cost functions. Health Econ 1999; 8(6) : 521-30.

[56] Aletras V, Kontodimopoulos N, Zagouldoudis A, Niakas D. The short-term effect on technical and scale efficiency of establishing regional health systems and general management in Greek NHS hospitals. Health Policy 2007; 83(2-3): 236-45.

[57] Aletras V. The perfect size of the NHS hospitals in Greece. Greek Med Rec 1998; 64(5-6):408-15.

[58] Aletras V. The economic analysis of the hospital wards, an econometric approach, PHD study. Aristotelio University of Thessaloniki, Thessaloniki 1997a.

[59] Androutsou L, Geitona M, Yfantopoulos J. Measuring efficiency and productivity across hospitals in the regional health authority of Thessaly in Greece. J Health Man 2011;13(2): 121-40.

[60] Aletras V. Theoretical and empirical analysis of the x- efficiency of the NHS hospitals. Greek Med Rec 1997b; 14(6): 662-74.

[61] Kontodimopoulos N, Papadakis O, Ioannidis J, Niakas D. Measuring the efficiency of the public and private renal units in Greece, Greek medical records. Health Econ 2005; 22(6): 606-13.

[62] Kontodimopoulos N, Niakas D. A 12-year analysis of malmquist total factor productivity in dialysis facilities. J Med Syst 2006; 30: $333-42$. 
[63] Kontodimopoulos N, Nanos P, Niakas D. Balancing efficiency oh health services and equity of access in remote areas in Greece. Health Policy 2006; 76: 49-57.

[64] Geitona M. Mapping of hospital care in Greece. Regional inequalities in health. Iatriki 2001; 79 (3): 259-67.

[65] Geitona M, Yfantopoulos J. Financing public hospitals in Greece 1922-1992. Iatriki 1995; 67(2): 133-141.

[66] Mossialos E, Allin S, Davaki K. Analysing the Greek health system: a tale of fragmentation and inertia. Health Econ 2005; 14 (1): 151-68.

[67] Geitona M, Androutsou L, Theodoratou D. Cost estimation of patients admitted to the intensive care unit: a case study of the teaching university hospital of Thessaly. J Med Econ 2010; 13 (2): $179-84$.

[68] Economou B, Giorno C. Improving the performance of public health care system in Greece. Economic department working paper. Organisation of Economic Co-operation and Development. English. ECO/WKP 2009; 722: 63.

[69] Ministry of health and Social Solidarity records Dec 31, 2011.

[70] Memorandum of economic and financial policies, and technical memorandum of understanding. Greece and the IMF, July 4, 2011.

[71] Farrell MJ. The measurement of productive efficiency. J R Stat Soc 1957;120(3):153-281.

[72] Coelli T, Rao P, O'Donnell C, Battese G. An introduction to efficiency and productivity analysis. Boston: Kluwer 2005.

[73] Thanassoulis E. Introduction to the theory and application of Data envelopment analysis. Boston: Kluwer 2001.

[74] XLDEA, DEA package. Available from: http://www.top4download.com/xldea/screenshot-jqjlhglw.html

[75] Ozcan YA, Lynch JR. Rural hospital closures: an inquiry into efficiency. Adv Health Econ Health Ser Res 1992; 13: 205-44.
[76] Mobley L, Magnussen J. An international comparison of hospital efficiency. Does international environment matter? Appl Econ1998; 30: 1089-100.

[77] Jacobs R. Alternative methods to examine hospital efficiency: data envelopment analysis and stochastic frontier analysis. Health Care Man Sci 2001; 4:103-15.

[78] Grosskopf S, Valdmanis V. Evaluating hospital performance with case mix adjusted outputs. Med Care 1993; 31(6): 525-32.

[79] Byrnes P, Valdmanis V. DEA in hospital management: analysing technical and allocative efficiency in Charnes A, Cooper WW, Lewin AY, Seiford LM, Eds. Data envelopment analysis: theory, methods and applications. New York: Oxford University Press 1995.

[80] Ehreth JL. The development and evaluation of hospital performance measures for policy Analysis. Med Care 1994; 32 (6): 56887.

[81] White KR, Ozcan YA. Church ownership and hospital efficiency. Hosp Health Ser Admin 1996; 41(3): 297-310.

[82] Al-Shammari M. A multi-criteria DEA model for measuring the productive efficiency of hospitals international. J Open Prod Man 1999; 19(9): 879-90.

[83] Sarkis J, Talluri S. Efficiency measurements of hospitals: Issues and extentions. Int J Open Prod Man 2002; 22(3): 306-13.

[84] Steinman L, Dittrich G, Karmann A, Zweifel P. Measuring and comparing the (in) efficiency of German and Swiss hospitals. Eur J Health Econ 2004; 35: 216-26.

[85] Siciliani L. Estimating technical efficiency in the hospital sector with panel data: a comparison of parametric and non-parametric techniques. Appl Health Econ Health Policy 2006; 5(2): 99-116.

[86] Staat M. Efficiency of hospitals on Germany: A DEA-bootstrap approach. Appl Econ 2006; 5: 216-26.

Received: August 28, 2012

(C) Geitona et al.; Licensee Bentham Open.

This is an open access article licensed under the terms of the Creative Commons Attribution Non-Commercial License (http://creativecommons.org/licenses/by-nc/3.0/) which permits unrestricted, non-commercial use, distribution and reproduction in any medium, provided the work is properly cited. 